\author{
Cadernos de \\ ESTUDOS LINGUIISTICOS - (59.1), Campinas, pp. 7-22 - jan./abr. 2017
}

\title{
CONTEXT AND DISAGREEMENT
}

\author{
ISIDORA STOJANOVIC
}

\begin{abstract}
This paper is an occasion to take stock of the place that the argument from faultless disagreement has occupied in philosophy of language in the last fifteen years, in particular in the debate between contextualism and relativism. The survey offered in the first part of the paper appears to show that the phenomenon of disagreement fails to provide any strong motivation for adopting any novel semantic framework, contrary to relativists' claims. But, on a more positive note, the interest in disagreement has allowed us to better understand how language works. The second part of the paper explains how the fine-grained structure of meaning - at the level of words, sentences and even entire discourse - reveals a variety of sources that may lead discourse participants to disagree.

Keywords: faultless disagreement; contextualism; relativism.
\end{abstract}

RÉSUMÉ: Dans le présent article, nous allons nous pencher sur le rôle que l'argument du désaccord sans faute a joué dans la philosophie du langage au cours de ces quinze dernières années, notamment dans le débat entre le contextualisme et le relativisme. La discussion présentée dans la première partie de l'article démontre que le phénomène du désaccord ne fournit pas de motivation valide pour changer de cadre sémantique, contrairement à ce que maintiennent les partisans du relativisme. Cependant, l'étude du désaccord a permis d'avancer dans la compéhension de la nature de la communication et du langage. Dans la deuxième partie de l'article, nous expliquerons comment la fine structure de la signification - au niveau des mots, phrases, et même du discours tout entier - recèle une variété de sources qui peuvent conduire au désaccord et à la dispute.

Mots-clés: désaccord sans faute; contextualisme; relativisme.

\section{THE ARGUMENT FROM DISAGREEMENT: HOW IT STARTED, HOW IT ENDED}

I would like to start the paper with a concise and hopefully unbiased survey of the argument from faultless disagreement, and its role in the contextualismrelativism debate. The survey has a double purpose. One is to provide information for those who are not familiar with the debate; another is to take stock of the relevant discussions that have taken place in the past fifteen years, and, in doing so, clarify my own contribution to the debate.

Faultless disagreement has been one of the most vividly debated topics in the recent years - and for a good reason, since it does involve something of a puzzle.

* Institut Jean-Nicod (CNRS \& ENS, PSL Research University), Paris, France. isidora. stojanovic.nicod@gmail.com 
In what follows, I will present the puzzle in neutral terms, and will then sketch, in rough lines, the argument that the relativists (well, some of them) have built upon the puzzle for their view and against the rival invariantist and contextualist views. I will then go through some of the main responses that the argument has elicited in the literature, which, taken together, lead to the conclusion that the choice between contextualist and relativist (or, for that matter, invariantist) semantics is pretty much orthogonal to the account of disagreement.

The puzzle is presented typically in form of a dialogue, either using a predicate of personal taste, of which 'tasty', 'delicious' and 'fun' have been seen as paradigms, or using expressions that reflect one's information state, of which modal auxiliaries 'might' and 'must' have been seen as paradigms. The dialogues are meant to reflect the sort of natural and spontaneous dialogue that people might have, say, in discussing food (in the case 'tasty' or 'delicious'), activities (in the case of 'fun'), eventualities (in the case of epistemic modals), and so on. ${ }^{1}$ Here is an example: ${ }^{2}$

\section{Kathy: "This is delicious." Rob: "No, it isn't."}

The dialogue is taking place in a restaurant, and 'this' refers to finely chopped fresh parsley. Suppose that Kathy loves parsley, and Rob hates it. Firstly, if the parsley at stake tastes delicious to Kathy, and it tastes awful to Rob, it seems that they are both right, and that they are both saying something correct, or even true. At any rate, neither of them seems to be wrong in the way one would be in making a false claim, such as "São Paulo is to the North of Rio de Janeiro". Secondly, it also seems that they are in disagreement, which is indicated by Rob's use of the negation particle 'no', as well as his asserting the negation of the sentence

\footnotetext{
${ }^{1}$ For the sake of convenience, I will be mainly talking about predicates of personal taste, and will leave aside epistemic modals. I hope that nothing crucial hinges on that.

${ }^{2}$ While the examples in the literature are typically made up, I tried searching for a real life example. I have performed google searches with "tasty. No, it isn't" and "delicious. No, it isn't". The downside of google search is that it is not limited to dialogues, but the advantage is that the amount of data it covers is amazingly large. Somewhat surprisingly, the search with 'tasty' did not yield a single disagreement dialogue of the form "Vegemite is tasty. No, it isn' $t$ " - other than those used in philosophy papers. The same can be said about 'delicious', with one exception, namely this rent entitled "Fuck parsley": "Seriously. Who could legitimately put parsley in their mouth have it chomped up and rubbed all over their taste buds and say "Wow this is delicious". No it isn't and you must be lying. Oh look at this green bitter, dry, rough piece of shit on my plate that they have just put there to give the plate some color. If you want to put color on my plate just print a copy of a picasso on A4 paper and place it on top of my meal, because I would rather eat that than that useless green poor excuse for an edible substance. Just to be clear, I am not at all a fussy eater. I eat absolutely everything from all corners of the globe and I've even eaten animals I didn't even know existed in China. So it's not that. It's just, fuck you parsley." In the dialogue in (1), Rob stands Rob Millsy, the author of the rent, and Kathy is Kathy Gunst, a chef who likes parsley. Here are the relevant internet sources:

https://www.reddit.com/r/rant/comments/2y1hj2/fuck parsley/

http://hereandnow.wbur.org/2015/04/01/parsley-recipes-kathy-gunst
} 
asserted by Kathy. Thirdly, if disagreement is to be genuine, it seems that this should preclude the possibility that both parties may be right. While each of the three intuitions looks plausible when considered on its own, taken together, they are in tension (or even in contradiction).

I suggest that the term "faultless disagreement" be used to describe the real phenomenon that arises when we have dialogues that trigger those three intuitions. Granted that there is solid empirical evidence that there is such a phenomenon (and I don't think that anyone in the debate disputes this), the theoretical question that arises is how one should account for those seemingly inconsistent intuitions. The early relativist literature yields the following picture of the repartition between the possible theoretical positions. Invariantism would be the view which seeks to explain away the first intuition: it may seem that both parties are right, but they really aren't. Contextualism would be the view that seeks to explain away the second intuition: it may seem that there is disagreement, but there really isn't. Finally, relativism would be the view that does away with the third intuition, and seeks to demonstrate that there can be genuine disagreement even when both parties are right.

We'll shortly see that this picture is not completely accurate, and in particular, that contextualism encompasses several views that accept that there can be disagreement and are perfectly able to account for it. In the remainder of this section, I will first look at the way in which certain relativists have attempted to account for faultless disagreement, and explain why their attempt has failed. Then I will go through some more successful contextualist attempts to account for disagreement.

\subsection{The argument from disagreement as an argument for relativism}

The argument from faultless disagreement to semantic relativism may be seen as taking the form of an inference to the best explanation. Caricaturing perhaps a bit, a relativist would argue along the following lines. ${ }^{3}$ Step one. The three intuitions that we are confronted with (faultlessness, disagreement, and disagreement-precludes-faultlessness) are not on a par. The first two are more robust and both of them ought to be upheld. (This is why they think that neither invariantism nor contextualism are viable positions.) Hence we must give up the third intuition, and make room for a notion of disagreement that does not preclude that both parties may be right. Step two. The best way to make room for such a notion is by allowing for contents whose truth depends on an agent (or assessor, or judge). What it takes for two parties to disagree is that one party asserts some content, and the other party rejects that same content. This is compatible with the idea that both parties are right - provided, of course, that the content over

${ }^{3}$ I think that it is fair to attribute this line of argument to Kölbel (2002), Lasersohn (2005), and Egan et al. (2005), Stephenson (2007), Richard (2008). Shortly we will see that the view in MacFarlane (2014) is more elaborate. 
which they disagree is true when assessed from (or evaluated at) the one party, and false when assessed from/evaluated at the other party. The relativist semantic framework, in which contents are defined as mappings from agents (also called assessors or judges) and other parameters, such as worlds and times, to truth values, would then yield a straightforward account of faultless disagreement.

I will focus here on only one line of criticism, which is the one that I advanced in Stojanovic (2007). ${ }^{4}$ It goes as follows. Assume, for the sake of the argument, that we are operating with a relativist semantics, on which contents are mappings from agents (and other parameters) to truth values. Assume furthermore that speakers are semantically competent, in the sense that they are aware that a statement of the form "This is delicious" is apt to bear a truth value only when it is evaluated at an agent (or whatever other suitable parameter). Then, looking at the example in (1), Kathy knows that the content that she is asserting is true or false depending not only on what the world is like, but also on the judge. The same goes for Rob when he denies the content asserted by Kathy. Now, if Kathy intends the content that she is asserting to be evaluated for truth at herself, and if Rob intends the denial of that content to be evaluated for truth at himself, then it is no longer clear why they should be seen as disagreeing. For both of them know that one and the same content may take different truth values when evaluated at different agents, and they also know that the one's assertion and the other's denial of the same content are inconsistent only when evaluated with respect to the same agent. Hence if each party intends the asserted content to be evaluated at himself or herself, and if this is mutually clear between them, then they must realize that there is no clash in truth value between their respective claims (when evaluated for truth as they each intend them to be), and that their apparent disagreement must be driven by something else than aiming at truth.

The rebuttal of the relativist's argument that I have just sketched is formulated for a simple version of the relativist framework, namely, the one that defines contents as mappings from parameters that include agents (judges, assessors) to truth values, and that does not stipulate that there is a determinate way in which the context of utterance would fix the values at which the truth of the content is to be evaluated. This is the framework of Kölbel (2002) and Lasersohn (2005), but not that of MacFarlane (2014), who, in the formal framework, introduces a distinction between contexts of utterance and contexts of assessment. While there are genuine formal differences between the simpler framework and MacFarlane's, that does not make the latter better suited to account for the puzzle. For assume Kathy and Rob to be competent speakers; they must be aware, then, that their claims can only be evaluated for truth with respect to a context of assessment. If Kathy intends her claim to be evaluated with respect to her own context of assessment, and Rob intends his denial of Kathy's claim to be evaluated with respect to his own context,

\footnotetext{
${ }^{4}$ I think that the same line of criticism has been noted by other people as well, which comes as
} no surprise, since it is quite straightforward. 
and if this is mutually clear between them, then we have hardly made any progress towards an explanation of their presumed disagreement.

MacFarlane is aware that the formal framework does not by itself provide any account of disagreement. He does offer such an account, though, by positing two norms of assertion, a truth norm (2014: 102-103), and a retraction norm (2014: 108). Regardless of the problems and/or merits of MacFarlane's proposal, what matters for our present purposes is that, although the two norms are formulated by presupposing a distinction between contexts of utterance and contexts of assessment, the gist of his explanation is not at all bound up with relativism qua semantic framework. ${ }^{5}$

\subsection{The argument from disagreement as an argument against contextualism}

The argument from disagreement has triggered a large number of responses. In what follows, I will focus on five, which I take to be the most important. All five have been made (unless I am mistaken) on behalf of contextualism, though some responses work equally well on behalf of invariantist approaches. ${ }^{6}$ Let me stress from the outset that these approaches should not be seen as competing with each other but, rather, as complementing each other, and sometimes even as overlapping. I label them as follows, and will discuss them in this order: (i) the underdetermination approach; (ii) the metasemantic approach; (iii) the metalinguistic approach; (iv) the presuppositional approach; (v) the attitudinal approach.

The underdetermination approach. I start with this one not only because it is the one that I proposed in Stojanovic $(2007)^{7}$ but also because it was one among the first to have been put forward. It goes as follows. The intuitions of faultlessness and of disagreement that dialogues such as (1) trigger are not to be taken at face value. At a first glance, such a dialogue may well trigger those two

${ }^{5}$ This is admittedly a bit quick, but I will not go into further elaboration in this paper in part of lack of space, and in part because I believe that MacFarlane's explanation is on the wrong track. In particular, it has been shown in Kneer (2015) that almost no ordinary speaker subscribes to the norm of retraction either in the case of taste statements or in the epistemic case. Kneer tested both for retraction and for reassessment of truth value regarding claims such as "Fishsticks are tasty" that a person made at an earlier time (when they used to find them tasty) and was asked to reassess from a later time (when they no longer found them tasty). Ordinary speakers do not think that the change of taste makes the earlier claim false, nor do they think that a person is required to retract their claim. I am also skeptical that MacFarlane's formal account presents any advantage over the simple relativist account; see Stojanovic (2012b) for further details.

${ }^{6}$ Invariantist semantics, which would be a semantics that analyses a predicate such as 'tasty' or 'fun' as a predicate that either applies to an object or doesn't, is not plausible from a linguistic point of view. Such predicates are gradable adjectives, and if they are to be such that their application conditions are context-insensitive, then they should correspond to so-called absolute gradable adjectives, such as 'open' or 'straight' (see Kennedy and McNally 2005). At the very least, predicates of taste have thresholds that may vary with the context, which already requires a contextualist semantics.

${ }^{7}$ In Stojanovic (2007), I did not use the term "underdetermination"; I only did so in Stojanovic (2012a). 
intuitions, but in order to know whether we have a case of genuine disagreement (i.e. disagreement over the truth of a statement), or rather, a case in which the two parties are expressing their own preferences, we need more information about the context, and in particular, on how such a dialogue may evolve. I speculated that the meaning of the claims under consideration can be made more specific, and receive different readings. For example:

2. Kathy (talking about parsley): "This is delicious".

Rob: "No, it isn't."

Kathy: "Well, look, all I mean is that to me it is delicious."

Rob: "OK, fair enough. But to me, it tastes like a bitter, dry and rough piece of rubbish, and I just can't understand how anyone can like it."

3. Kathy (talking about parsley): "This is delicious".

Rob: "No, it isn't."

Kathy: "Yes it is. And I don't just mean that $I$ like it. It is delicious, to anyone."

Rob: "You are completely wrong. It isn't delicious, it tastes like a bitter, dry and rough piece of rubbish."

The way in which the dialogue in (2) evolves suggests that the intended reading for Kathy's initial claim is one on which she occupies the relevant experiencer argument, while the way in which it evolves in (3) suggests that the intended reading is a generic one, that is to say, that the experiencer argument is bound by a covert generic operator (see e.g. Moltmann (2010) and Pearson (2013) for the idea that taste predicates are covertly generic). Consequently, (2) provides a case in which the faultlessness intuition wins, so to speak, whereas (3) provides a case in which Kathy and Rob disagree, pretty much in the way in which they might disagree over the truth of some general descriptive claim, such as, say, the claim that parsley contains more iron than cilantro does.

One issue that is important and that I did not address in Stojanovic (2007), but did so in Stojanovic (2012a), is the question of what kind of evidence could ultimately settle a disagreement such as the one in (3). In this respect, the underdetermination approach goes only part of the way towards accounting for the general phenomenon. ${ }^{8}$

Themetasemantic approach. Glanzberg (2007) provides anotherearly response to the argument from disagreement, similar in spirit to the underdetermination approach. Glanzberg's focus, though, is on the nature of adjectives and, in particular, the fact that, qua gradable adjectives, their semantics requires scales and thresholds at which sentences containing such adjectives are to be evaluated.

\footnotetext{
${ }^{8}$ A contextualist semantics for predicates of personal taste in the same spirit of the one I sketched in Stojanovic (2007), albeit more elaborate, is defended e.g. in Sæbø (2009) or Bylinina (2014), although these authors are not particularly concerned with disagreement.
} 
Relying on the significant semantic literature on adjectives, including Bierwisch's (1989) work on multidimensional adjectives, ${ }^{9}$ Glanzberg sets out to propose a contextualist account of predicates of personal taste, in line with the semantics of other gradable adjectives. To be sure, adjectives such as 'tasty' and 'fun' are not as simple as adjectives such as 'tall'. While 'tall' has a single conventionally associated scale, namely, height, 'fun' and 'tasty' may requires multiple scales. But, as he notes, "this is not a feature specific to adjectives of personal taste. Many gradable adjectives can be associated with multiple scales. For instance, someone can be smart as in 'book smart' or 'street smart', a large city can be large in population, geography, etc." (2007: 10). Secondly, predicates of personal taste involve response-dependent properties. It makes little sense to think of tastiness as a property that an object can possess in itself, independently of there being some individual who could potentially experience its taste (and similarly for 'fun'). Glanzberg (2007) is relatively uncommital regarding the status of the experiencer argument. He does not posit it as a bona fide hidden argument, but writes: "To take response dependence into account, we will need to see the scales associated with tasty and fun to be experiencer-involving scales" (2007: 13). Finally, the gist of his rebuttal of the argument from disagreement is to point out that fixing all the different values of all those different parameters, in a context, is no straightforward matter and requires what he calls "indirect metasemantics." He similarly believes that whether there is genuine disagreement or not may depend on the context: if all the relevant parameters, that is to say, scales, experiencers and thresholds, are the same for Kathy's and Rob's utterances, we do have disagreement; but if the scale that is relevant to interpreting Kathy's utterance differs from the one relevant to interpreting Rob's utterance (as will happen, for example, if the experiencers relevant to fixing her scale are, say, food connaisseurs, and the ones relevant to fixing his scale are people in general), then it is no longer clear that they are disagreeing - or rather, it is no longer clear what it is that they are disagreeing about. For, in a sense, their disagreement turns on the question of how to fix the scale relevant for interpreting 'tasty' and, in this respect, the proposed account anticipates the gist of the metalinguistic approach, to which I now turn.

The metalinguistic approach. Sundell (2011) may be seen as the most fierce defender of the metalinguistic approach. There is some overlap between his proposal and both the underdetermination and the semantic approach, since all three hold that a dialogue that at a first glance may look like a disagreement in which the two parties disagree about whether some object has a certain property (e.g. whether tastiness is a property of parsley) may turn out, upon scrutiny, to be a disagreement about questions such as what counts, in a given context, as "tasty". The negotiation of scales and standards is thus seen, in the metalinguistic approach, as what often drives our disagreements not only on matters of taste, but also on aesthetic matters (see Sundell 2017) or on moral matters (see Plunkett and

${ }^{9}$ For a more up-to-date study of multidimensional adjectives, see Sassoon (2013). 
Sundell 2013). One of the key points of this approach is to argue that even though disagreement very often turns out to be a metalinguistic disagreement, this does not make it less significant than other kinds of disagreements. The authors also point out that in ethics and aesthetics, disagreements are often about the very concepts themselves. Thus in disagreeing, say, whether discussions in analytic philosophy are agressive, we may agree on which criteria make a discussion agressive, and disagree whether the discussions in analytic philosophy are such, but we may also disagree about the very criteria that make a discussion count as an agressive one. (This is my example, not theirs; but I take it that it illustrates their general point.)

The presuppositional approach. Presupposition is one of the most central phenomena in language, and we will shortly see that there is more than one way in which this notion is relevant to understanding, at least from a linguistic point of view, why one may be led to disagree with a statement made by somebody else. However, in the present context, by the presuppositional approach I mean the approach that Dan López de Sa has been pursuing since the beginning of the debate (see López de Sa (2008), (2015)), also discussed in Marques and García-Carpintero (2014). What the presuppositional approach shares with the first two approaches is the idea that, taken at face value, a dialogue such as (1) may turn out to be a genuine case of disagreement, but it need not be. The way the presuppositional approach accounts for this idea is that we start from the assumption that there may be different standards of taste, which hardly anyone disputes. But while we know that tastes do differ, when we use a predicate of personal taste, we normally presuppose that our interlocutors share our taste. If I take you to my favorite restaurant, and I tell you that a certain dish is delicious, that may help you decide what to order partly because we presuppose that our gustatory tastes are alike. This kind of presupposition is what López de Sa calls a presupposition of commonality. Now when we enter into a disagreement, and the presupposition is satisfied that is to say, we do have a similar taste, then we disagree indeed, although it is no longer a faultless disagreement. For if the two interlocutors share the same standard of taste, and the standard is determinate enough, then relative to that standard, either a sentence or its negation can be true, but not both. On the other hand, if our standards of taste diverge significantly, then the presupposition fails, and a linguistic exchange of the from "This is delicious - No, it isn' $t$ " becomes deficient in a similar way in which (adapting a famous example from David Kaplan) if I presuppose that the person at whom I am pointing is Rudolf Carnap, and you presuppose that it is Spiro Agnew, and I say "He is a famous philosopher" and you reply "No, he isn't", we are not really disagreeing.

The attitudinal approach. The last line of response to the relativists' argument from disagreement that I want to mention takes inspiration from expressivism (see e.g. Gibbard 1992). As is well known, for an expressivist, an evaluative statement is not in the business of stating facts, but rather, it aims at expressing the speaker's attitude. When Rob and Kathy disagree over the deliciousness of parsley, they are not trying to determine what parsley is factually like, but rather, Kathy is expressing her positive attitude towards parsley and Rob, his negative attitude. This clash of attitudes constitutes a genuine disagreement (or so the idea goes). 
If such a disagreement in attitude is already able to account for the disagreement intuition in cases such as (1), then the semantic interpretation of what Kathy and Rob are saying is, in a way, beside the point. Even if they stated their preferences using the first person pronoun, as in (4) below, they would still be disagreeing in the relevant sense:

4. Kathy: "I like parsley".

Rob: "I dislike it."

Although the idea derives from expressivism, an expressivist semantics is not required to deploy this kind of mechanism as an explanation of why we perceive disagreement in cases such as (1). The same strategy becomes available to contextualists, or even invariantists. For a development of this line of reply, see, inter alia, Huvenes (2012) and Marques (2014, 2015).

With this, I close the survey of the argument from disagreement and the role that it has played in the contextualism-relativism debate. To be sure, the survey does not claim to be exhaustive, and there are other strategies that have been proposed. In the next section, I will draw some lessons regarding the relationship between theory of meaning and theory of disagreement, and will argue that these explanations of what is going on are not mutually exclusive but, to the contrary, often work together, as I will show on a concrete case.

\section{THE LINGUISTIC COMPLEXITY OF DISAGREEMENT: A CASE- STUDY}

Based on the discussion from the first part of the paper, and in general, on a critical assessment of the place that the argument from disagreement used to occupy but gradually lost, it is tempting to draw a negative conclusion about the relationship between disagreement and semantics. On the one hand, it is widely agreed nowadays that relativist semantics per se, be it some simpler version as in Kölbel (2002) or Lasersohn (2005), or a more cumbersome version as in MacFarlane (2014), does not yield a straightforward account of disagreement. This is conceded even by the proponents of relativism, as witnessed by the need in MacFarlane (2014) to develop a heavy normative machinery to handle disagreement. On the other hand, as revealed through the various responses to the argument from disagreement, non-relativists have a range of different mechanisms (semantic, pragmatic, cognitive) to which they can appeal in order to shed light on what is happening in various cases of disagreement over matters of taste. Several of these mechanisms are not tied to a contextualist semantics, but are available to almost equal degree to contextualists, relativists, invariantists and even expressivists.

Based on this, one may be tempted to think that semantics, that is, the theory of meaning, and the theory of disagreement, have nothing to do with each other. The intended take-home message of this paper is that we should resist such a 
pessimistic conclusion. The study of disagreement has, to the contrary, been a fruitful and constructive enterprise that has made it possible to reach a better understanding of the fine-grained meaning structure that the expressions and constructions at stake possess. Looking at disagreement does teach us stuff about semantics - although not quite the lesson that the relativists wanted us to draw. Conversely, understanding the different aspects of meaning provides valuable insight into the reasons that may drive people into disagreeing.

The remainder of the paper is expands on this optimistic conclusion by looking at a real life case of a disagreement regarding hipsters. My case study is based on an online discussion about hipsters, under the title "Why do so many people hate "hipsters"?" I have selected from it a series of excerpts, listed below, that are meant to help me illustrate some of the previous theoretical observations regarding disagreements. ${ }^{10}$

8. I see a lot of hate for the hipster crowd and I can't really understand why. I myself am not a hipster. But I do know a LOT of people who could be considered to be hipsters and they are all really nice, well educated people. Usually very friendly people who would give you the shirt off their back if you needed it. And when it comes to music, politics, whatever... I have never gotten the music snob vibe from them, more so awesome suggestions of some music I might not of heard.

9. I don't hate hipsters as people, I hate the hipster aesthetic because it is insincere. As I see it, hipsterdom is based on the notion that individualistic authenticity can be bought and displayed as a piece of fashion. Obviously, this is self-contradictory, and it pisses me off to no end.

10. The insincerity aesthetic is a little irritating, but I find the accompanying pretentiousness to be the most annoying part.

11. "Hipsters" are trend-eating, fad-mongering, consumer-whores that dress up like each other, while blindly reinforcing and building the corporatocracy they ostensibly revile. It doesn't involve any sort of creativity or intellectualism to be a hipster.

12. I don't understand why some people, myself included, are automatically "trend whores" when all we do is buy clothes we think make us look nice.

13. It is socially acceptable to hate them. Take as fact that most people crave acceptance. A way to feel a part of a group is to extol views and ideas that are already widely accepted. Given that reddit is a place where it is already popular to hate on hipsters, simply agreeing or propagating that sentiment will result in acceptance. (...) This is similar to the way that

${ }^{10} \mathrm{I}$ have perhpas included more excerpts that I need to make my points, but they provide a more complete background for the discussion of the specific examples. The details of the discussion may be consulted here: https://www.reddit.com/r/AskReddit/comments/fppfl/why_do_so_many_people hate hipsters/ 
everyone seems to hate on socks and sandals. There is nothing inherently wrong with this, and in fact, it's very comfortable.

14. What bugs me is that there is this tacit assertion that it DOES take creativity and intellectualism to be a hipster. It's this completely hollow, passive-aggressive sense of superiority that bugs me. I actually sort of like the hipster look to be honest with you.

15. Because they're hypocritical. They try to be individual yet they're conforming to the same aesthetic. I don't dislike hipsters as people. I dislike hipsters as a persona. They're often pompous, arrogant, and snobbish; hating on me for my "mainstream" likes.

16. I always kinda saw your type of generalization and stereotyping as a tad bit ignorant and clueless. (as a reply to 15)

17. I always kinda sorta thought that passive aggressiveness and nonchalance were the trademarks of a hipster. (as a reply to 16)

18. I can't be a hipster because I'm fat; I can't fit in those skinny jeans and I look like an idiot in those flourescent raybans. That's why $I$ hate hipsters.

19. They're a commercialized and consumption-driven version of the "back to nature" movement, which is insulting to everyone who is genuinely trying to encourage a lifestyle that is basic and honest.

20. My main beef with hipsters is that they are, ostensibly, the type of people I would love to be good friends with. For the most part, they have a lot of good tastes, are more intelligent than the average human, are artsy, politically active, and individualistic. They are the people I hung out with, before they became hipsters.

21. When I think of hipsters I think of arrogant gits who are all snobby and elitist, and yet, also ignorant. If someone is that nice they're not really a hipster, by definition, because being kind is too mainstream.

22. I dress like how most would describe a "hipster" and get insulted almost every day for it. I dress like this because I care about fashion and I believe that I look nice in these clothes. I don't do it to be different or because I think it will make me "cool", I just feel good in these clothes. I don't hate on or think I'm better than people that dress other ways, yet it's always assumed I do. I typically just have to ignore the barrage of driveby insults I get daily because I know I'm happy how I am.

23. I think there's a difference between alternative lifestyles and being a hipster. Hipsters, to me, are all about devouring meaningful things and reducing them to their most consumerist, vapid incarnation. (...) It's a reactionary thing, experience something good in the world and then make it your own without actually adopting the principles. That's why it's something to be scorned.

The first thing that strikes one in this discussion is that it is, to a large extent, a disagreement in attitude. It is a disagreement between pro-hipsters and antihipsters, between people who like hipsters and those who dislike them, or even hate them. Interestingly, even though the leading question of the post is "Why 
so many people hate "hipsters"?", the nature of the replies and comments does not address that descriptive question (with (13) being a possible exception), but rather, it addresses something akin to a normative question along the lines of "Do "hipsters" deserve to be hated, and if so, why?"

The second striking observation is that, to a large extent, the discussion is meta-linguistic. An early indication of this metalinguistic character is the use of quotation marks with the word 'hipster' in the leading question itself, and quotes are used in several posts (e.g. (11), (22)). Other clear indications of the metalinguistic character may be seen in posts whose speakers explicitly address the question of what makes a hipster a "hipster", a nice example of which is (21), repeated below as (24):

24. When I think of hipsters I think of arrogant gits who are all snobby and elitist, and yet, also ignorant. If someone is that nice they're not really a hipster, by definition, because being kind is too mainstream.

The first sentence may be interpreted as a metalinguistic statement about which group of people the term 'hipster' refers to. Note also the use of the "by definition", a clearly metalinguistic device. Other neat illustrations of the metalinguistic nature of the disagreement are (14), (17), (22), and especially (23), in which the speaker contrasts the concept of leading an "alternative lifestyle" (presumably positively valued) and "being a hipster" (negatively valued). In "Hipsters, to me, are all about devouring meaningful things and reducing them to their most consumerist, vapid incarnation", the appositive "to me" works as a metalinguistic hedge that means something along the lines "the way I understand the term 'hipster"'.

I now turn to a third observation that percolates from this case study, and has to do with something fairly similar to López de Sa's presupposition of commonality. The kind of presupposition that lies in the background of the discussion over hipsters is certainly not the presupposition that the different participants in the debate share the same taste. To the contrary, it is taken for granted from the start that the tastes are likely to depart considerably: the anti-hipsters will, in general, dislike those things that are highly valued according to the hipster taste, while the pro-hipsters will include many people who endorse the hipster taste. (Of course, there are exceptions, as in (14), in which the speaker expresses an anti-hipster stance, while admitting that he or she likes the hipster look, hence shares the hipster taste.)

The reason why López de Sa's explanation does not apply squarely onto the present case study is that the disagreement over hipsters is much more complex than, say, a disagreement over parsley. It is not, or at least, not exclusively, about taste. (Though taste, in a broad sense, is involved, such as music taste and fashion taste.) Some of the disagreement is aesthetic (as stressed e.g. in (9): "I don't hate hipsters as people, I hate the hipster aesthetic"), but a lot of the disagreement turns on issues that arguably belong to the moral realm. This is not surprising, given that the underlying normative question is whether a group of people deserves to be 
hated, which calls for ethics-related justifications. Hating somebody just because of the way they look is perceived, in our society, as wrong, hence, even if de facto some of the hipster-haters hate them because of the way they look, they will likely try to back up their claims with arguments having to do with some moral qualities that they ascribe to hipsters. And this is indeed what we see in many posts, where hipsters are described as insincere (9), pretentious (10), hypocritical (15), pompous (15), arrogant $(15,21)$, snobbish, snobby (15, 21), or elitist (21), all of which are thick terms that are used to convey negative value-judgements. ${ }^{11}$ Consumerism is another characteristic that various speakers appeal to (e.g. (11), (19), (23)) in order to justify their dislike for hipsters. Conversely, in pro-hipster posts, we can also pinpoint terms that have a positive valence: really nice, well educated, friendly (8), intelligent, artsy, politically active, individualistic (20). ${ }^{12}$

Turning back to the idea of a presupposition of commonality, we can see it at work in our case study in the following way. Although it is agreed from the start that the pro-hipsters and the anti-hipsters need not share their tastes, both sides presuppose that they share some more general values. For instance, they mutually take it for granted that the qualities of arrogance and insincerity are bad qualities - and then, some anti-hipsters claim that these are, in general, qualities possessed by hipsters, while pro-hipsters balk at this kind of generalization. As a general pattern, the two sides in a dispute often agree on some more basic set of values or, more precisely, they presuppose that they share some more basic set of values -, which in turn makes it possible for them to rationally disagree over partially normative issues, such as whether hipsters are dislikeable.

Just as this case study illustrates some presuppositions of commonality that are in place, it also serves to illustrate what happens when such a presupposition breaks down. Thus a couple of anti-hipster posts, e.g. (9), (11), or (19), aim to back up their dislike of hipsters by describing them as fashion-followers who care about trends, and, importantly, by assuming that to have this sort of property is bad, and that its badness must be mutually acknowledged. In (12) and (22), however, the speakers explicitly address - and reject - the presupposition that dressing like a hipster and caring about fashion is in any way bad. The clash between the two sides in this case is, then, one in which the relevant presupposition of commonality no longer holds: one side values interest in fashion negatively, while the other side does not value it negatively. There still is a disagreement, but one which is now about the sets of values that the two disagreeing parties endorse respectively.

${ }^{11}$ In Cepollaro and Stojanovic (2016), we propose a presuppositional account of thick terms and slurs. We analyze them as having a certain descriptive content while at the same time triggering an evaluative presupposition. For example, the term 'arrogant' would refer to people who behave in a certain way, and at the same time, it would trigger the presupposition that people who behave in that way are bad because of that. We also discuss what happens when the interlocutor does not endorse the evaluative presupposition (as in the case of objectionable thick terms; see e.g. Väyrynen (2009)).

${ }^{12}$ It is at least controversial whether 'artsy', 'politically active', or 'individualistic' should be considered as thick terms, and my own view would be that there are not, to the extent that no positive (or, for that matter, negative) valence is associated with those terms as a matter of their meaning. But in the present context, they are clearly used by the speaker of (20) in order to convey a positive valuejudgement. 
To take stock, we see several disagreement patterns:

(i) a metalinguistic disagreement over who counts as a "hipster": people who are nice, well-educated, art-lovers etc. vs. people who have distorted the original idea and have turned it into an elitist and consumerist fashion trend;

(ii) a factual disagreement over the properties that are attributed to a group: whether hipsters are, generally speaking, arrogant, pretentious and insincere or, to the contrary, really nice and friendly; in this case, the two sides converge in valuing arrogance, pretentiousness and insincerity negatively, and niceness and friendliness positively;

(iii) a disagreement in values: the two parties may agree on a property that they attribute to hipsters as a group, for instance, that they like to dress in a certain fashion, yet they disagree whether having this property has any bad implications or not.

By way of wrapping up this case study, let me note that here, we did not see any support for either the metasemantic or the underdetermination approach. This should come as no surprise, because those two specifically aim at explaining why predicates of personal taste create dialogues that trigger intuitions of faultless disagreement. $^{13}$

My aim in this paper has been to discuss the role that considerations about disagreements over matters of taste (and similar subjective matters) have played in shaping the landscape of natural language semantics. I have argued that adopting a relativist semantic framework is neither necessary nor sufficient in order to understand what happens in the alleged cases of faultless disagreement. I have not argued against relativism per se - indeed, there are areas, such as metaethics, in which relativism constitutes an important and respectable tradition (see Stojanovic (2017) for discussion). My claim is, rather, that the phenomenon of disagreement does not straightforwardly motivate relativist semantics, and that, conversely, contextualist semantics has a variety of mecanisms at its disposal to account for the phenomenon. The take-home message of this paper is that the various contextualist strategies that arose in reply to the argument from disagreement actually reveal a variety of language-related sources that may lead people to disagree. These contextualist replies do not compete with each other but, rather, complement each

${ }^{13}$ This being said, there is one respect in which the underdetermination proposal may be relevant. For even in this case study, we can notice a contrast between expressing a purely first-personal attitude (like or dislike) towards hipsters vs. arguing that people in general ought to have a certain attitude (like or dislike) towards them. The contrast is illustrated, for example, by the emphasized used of the first person pronoun in (18): "That's why $I$ hate hipsters" as opposed to the generic construction "That's why it's something to be scorned" in (23). See also Stojanovic (2012a) for a related point concerning expressions of emotion. 
other. Disagreement is a complex phenomenon, in which context intervenes at many stages, as I have illustrated with a case-study.

\section{ACKNOWLEDGMENTS}

Earlier versions of this work were presented at the conference Faces of Disagreement in Montreal, Canada, on 27 May 2017, and at the University of Taiyuán, China, on 22 August 2017. I would like to thank the audiences at these events for helpful feedback, in particular Ethan Jerzak, Michele Palmira, Sarah Stroud, Christine Tappolet and Sandy Goldberg. I have also benefited from discussions with Julia Zakkou, Neftalí Villanueva, Teresa Marques and Dan Zeman. I am particularly grateful to Edwiges Maria Morato and Anna Christina Bentes for their invitation to contribute to the present issue. Finally, I acknowledge institutional support from the following grants: ANR-10-LABX-0087 IEC, ANR10-IDEX-0001-02 PSL, MINECO FFI2016-80636-P, and European Union's Horizon 2020 Marie Skłodowska-Curie grant agreement n. 675415.

\section{REFERENCES}

BIERWISCH, Manfred. The Semantics of gradation, in Bierwisch, M. and Ewald Lang (eds.), Dimensional Adjectives. Berlin: Springer-Verlag. 1989, 71-261.

BYLININA, Lisa. The Grammar of Standards: Judge-Dependence, Purpose-Relativity, and Comparison Classes in Degree Constructions. LOT Dissertation Series 347. Utrecht: LOT, 2014.

CEPOLLARO, Bianca and Isidora Stojanovic. Hybrid Evaluatives. Grazer Philosophische Studien. 2016, 458-488.

EGAN, Andy, John Hawthorne and Brian Weatherson. Epistemic Modals in Context, in Preyer, G. and Peter, G. (eds.) Contextualism in Philosophy, OUP. 2005, 131-168.

GIBBARD, Alan. Wise Choices, Apt Feelings: a Theory of Normative Judgement. Harvard University Press, 1992.

GLANZBERG, Michael. Context, Content and Relativism. Philosophical Studies. 2007, 136:1-29.

HUVENES, Torfinn. Varieties of disagreement and predicates of taste. Australasian Journal of Philosophy 90 (1):167-181, 2012.

KENNEDY, Christopher and Louise McNally. Scale structure, degree modification and the semantics of gradable predicates. Language 81:345-381, 2005.

KNEER, Markus. Perspective in Language. PhD dissertation, École des Hautes Études en Sciences Sociales, Paris, 2015.

KÖLBEL, Max. Truth Without Objectivity. Routledge, 2002. 
LASERSOHN, Peter. Context dependence, disagreement, and predicates of personal taste. Linguistics and Philosophy 28: 643-686, 2005.

LÓPEZ DE SA, Dan. Presuppositions of commonality: an indexical relativist account of disagreement, in Relative Truth, eds. M.García-Carpintero and M. Kölbel (Oxford: Oxford University Press). 2008, 297-310.

LÓPEZ DE SA, Dan. Expressing Disagreement: A Presuppositional Indexical Contextualist Relativist Account. Erkenntnis 80: 153-165, 2015.

MARQUES, Teresa and Manuel García-Carpintero. Disagreement about taste: commonality presuppositions and coordination. Australasian Journal of Philosophy 92: 701-723, 2014.

MARQUES, Teresa. Doxastic disagreement. Erkenntnis 79: 121-142, 2014.

MARQUES, Teresa. Disagreeing in Context. Frontiers in Psychology 6: 257, 2015.

MOLTMANN, Friederike. Relative Truth and the First Person, Philosophical Studies 150: 187-220, 2010

PEARSON, Hazel. A judge-free semantics for predicates of personal taste. Journal of Semantics 30:103-154, 2013.

PLUNKETT, David \& Sundell, Timothy. Disagreement and the semantics of normative and evaluative terms. Philosophers'Imprint 13: 1-37, 2013.

RICHARD, Mark. When Truth Gives Out. Oxford University Press, 2008.

SÆBØ, Kjell Johan. Judgement ascriptions. Linguistics and Philosophy 32: 327-352, 2009.

SASSOON, Galit W. A typology of multidimensional adjectives. Journal of Semantics 30: 335-380, 2013.

STEPHENSON, Tamina. Judge-Dependence, Epistemic Modals, and Predicates of Personal Taste. Linguistics and Philosophy 30: 487-525, 2007.

STOJANOVIC, Isidora. Talking about taste: Disagreement, implicit arguments, and relative truth. Linguistics and Philosophy 30: 691-706, 2007.

STOJANOVIC, Isidora. When (True) Disagreement Gives Out. Croatian Journal of Philosophy 11 (32):183-195, 2011.

STOJANOVIC, Isidora. Emotional Disagreement. Dialogue 51 (1): 99-117, 2012 a.

STOJANOVIC, Isidora. On Value-Attributions: Semantics and Beyond. The Southern Journal of Philosophy 50(4): 621-638, $2012 \mathrm{~b}$.

STOJANOVIC, Isidora. Metaethical Relativism, in McPherson, T. and D. Plunkett (eds.) The Routledge Handbook of Metaethics. Routledge. 119-132, 2017.

SUNDELL, Timothy. Disagreements about taste. Philosophical Studies 155: 267-288, 2011.

SUNDELL, Timothy. Aesthetic Negotiations, in Young, J. (ed.) The Semantics of Aesthetic Judgment. Oxford: OUP, 2017.

VÄYRYNEN, Pekka. Objectionable Thick Concepts in Denials. Philosophical Perspectives 23: 43969, 2009. 